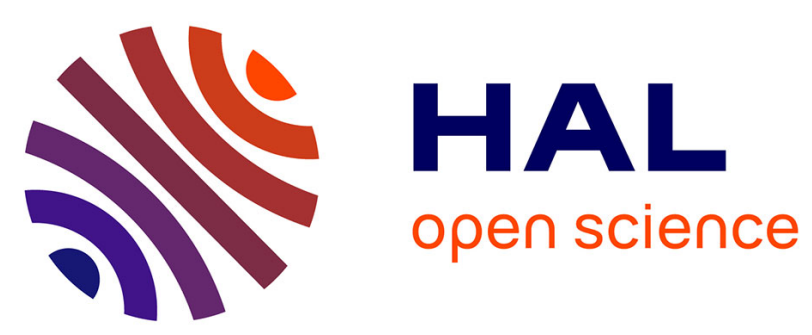

\title{
EXPERIMENTAL VALIDATION OF UNSTEADY MODELS FOR WIND/ SAILS/ RIGGING FLUID SRUCTURE INTERACTION
}

\author{
Benoit Augier, Patrick Bot, Frédéric Hauville, Mathieu Durand
}

\section{- To cite this version:}

Benoit Augier, Patrick Bot, Frédéric Hauville, Mathieu Durand. EXPERIMENTAL VALIDATION OF UNSTEADY MODELS FOR WIND/ SAILS/ RIGGING FLUID SRUCTURE INTERACTION. 2nd INNOV'SAIL International Conference on Innovation in High Performance Sailing Yachts $\times$ INNOV'SAIL 2010, Jun 2010, LORIENT, France. pp.1-238. hal-02103774

\section{HAL Id: hal-02103774 \\ https://hal.science/hal-02103774}

Submitted on 18 Apr 2019

HAL is a multi-disciplinary open access archive for the deposit and dissemination of scientific research documents, whether they are published or not. The documents may come from teaching and research institutions in France or abroad, or from public or private research centers.
L'archive ouverte pluridisciplinaire HAL, est destinée au dépôt et à la diffusion de documents scientifiques de niveau recherche, publiés ou non, émanant des établissements d'enseignement et de recherche français ou étrangers, des laboratoires publics ou privés. 


\title{
EXPERIMENTAL VALIDATION OF UNSTEADY MODELS FOR WIND/ SAILS/ RIGGING FLUID SRUCTURE INTERACTION
}

\author{
B Augier, P Bot and F Hauville, Research Institute of the French Naval Academy, France
}

M Durand K-epsilon, France

\section{SUMMARY}

The aim of this paper is to present the work of experimental validation elements of the aero elastic and unsteady model ARAVANTI. Numerical and Experimental results comparison is made on the rigging and sails of a J80 sail boat. Yacht modelling demands to consider unsteady phenomena resulting from the sea state, variations of wind speed and direction, yacht motion or trimming by the crew. A dedicated instrumentation is developed to measure the loads in shrouds and tension points of the sail, the apparent wind, the yacht motion, the sails flying shape and the navigation data. A special effort is made on sensors calibration, physical measurement comprehension and data synchronisation. Comparison with numerical results shows that the loads and flying shapes are well predicted by the model.

\section{NOMENCLATURE}

$\begin{array}{ll}\text { AWA } & \text { Apparent Wind Angle } \\ \text { AWS } & \text { Apparent Wind Speed } \\ \text { TWA } & \text { True Wind Angle } \\ \text { TWS } & \text { True Wind Speed } \\ \text { COG } & \text { Course Over Ground } \\ \text { W } & \text { Component of the wind vector along the } \\ & \text { mast direction } \\ \text { I } & \text { Distance from the deck to the jib sheave } \\ \text { P } & \text { Distance from the boom to the top mast } \\ \text { J } & \text { Distance from the mast to the jib tack } \\ \text { E } & \text { Distance from main tack to clew } \\ E_{p r e} & \text { Precision error of the sensor } \\ E_{h} & \text { Hysteresis error of the sensor } \\ E_{f} & \text { Fidelity error of the sensor } \\ E_{l} & \text { Linearity error of the sensor } \\ \mathrm{F} & \text { Centre of the buoyancy area at rest } \\ \text { MR } & \text { Measurements Range } \\ \mathrm{R}_{\mathrm{f}} & \text { Sail 3D reconstruction Reference plan } \\ \text { Se } & \text { Sensor sensibility } \\ \text { Shrouds: } & \\ \text { V1 } & \text { Vertical 1, external shroud (longest) } \\ \text { V2 } & \text { Vertical 2, intermediary shroud } \\ \text { D1 } & \text { Diagonal 1, internal shroud (shortest) } \\ \text { Suffix: } & \\ \text { po } & \text { Port side } \\ \text { st } & \text { Starboard sideSymbols: } \\ \beta & \text { Kurtosis, } 4^{\text {th } \text { order statistical moment }} \\ \lambda & \text { Skewness, } 3^{\text {rd } \text { order statistical moment }} \\ \sigma & \text { Standard deviation, 2 } 2^{\text {nd }} \text { order statistical } \\ \theta & \text { Moment } \\ & \text { Entry/Exit angle } \\ & \end{array}$

\section{INTRODUCTION}

A navigating sail boat is a dynamic system exposed to unsteady phenomena as the wind and the sea. Yacht response modeling demands to simulate the complex and changing environment. The present work is driven by the need to get unsteady measurements from an instrumented sail boat in real navigation conditions. Collected data are used to build a database for an aero elastic model validation. To measure loads in the rigging, ship attitudes, navigation data, adjustments and sails flying shape simultaneously a dedicated instrumentation has been developed. Figure 2 shows how full scale data and calculation code ARAVANTI are connected.

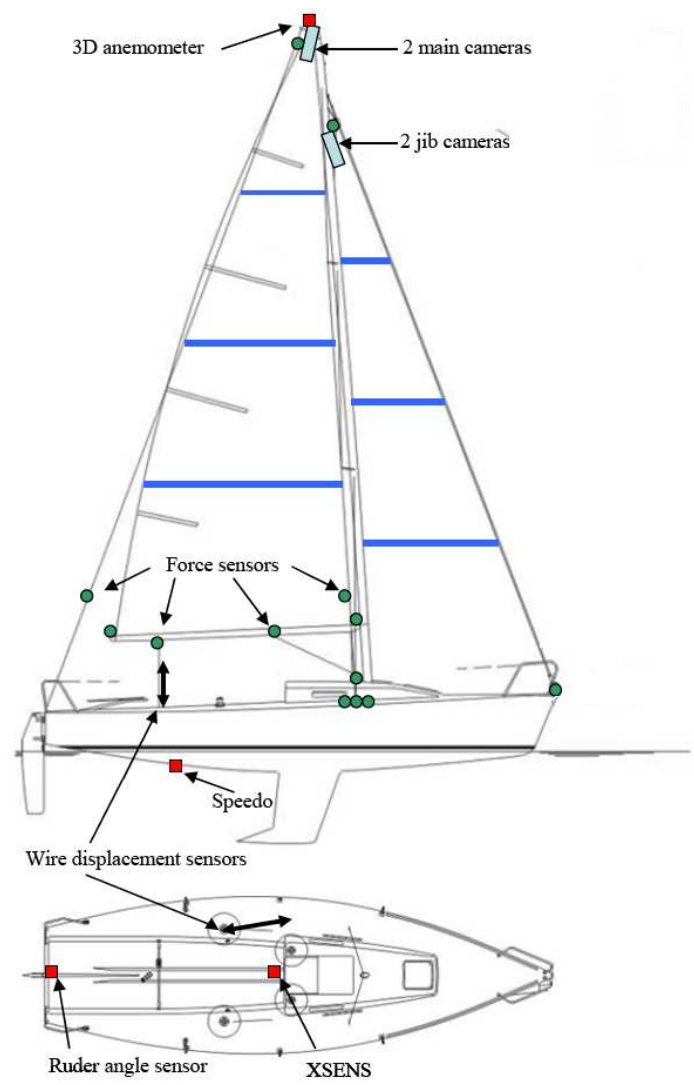

Figure 1. Plan of a J80 with principal sensors' position.

ARAVANTI is a fluid-structure model using a CST elements membrane model extended in 3dimensions [6]. Hypothesis imposed inside this element are constant stresses, constant strains and uniform stiffness of the material. Non-linearities coming from the geometry and compressions are taken into account. The calculation of the flow around the sails is carried out under the hypothesis of an incompressible inviscid fluid, using a particular method developed by Rehbach (Rehbach 
(1978)) and then Huberson (Huberson (1984). This method is, in essence, unsteady, taking into account the boundary conditions of the displacement velocities of the surface as well as an atmospheric wind gradient. The effects of the interaction are translated into a coupling of the kinematic equation (continuity of the normal component of the velocity at the interface between fluid and structure geometrical domains) and dynamic equations (continuity of the normal component of the external force, pressure forces, on the contact surface of the sail with the fluid).

ARAVANTI settings are given by yacht attitude recordings and calculation results are compared to the loads measured on navigation. Previous studies focused on specific sailing parameters like the aerodynamic or hydrodynamic forces with a dedicated sail force dynamometer boat DYNA or Fujin [1] [4], the flying shape and rig position [2], or the aerodynamic sail force [3]. The sailing boat problem is simplified to a small identified number of studied interactions, enough to be a tough work. Wind tunnel experimentation gives very accurate information on the apparent wind angle and apparent wind speed. AWA and trim are controlled. All those parameters are fixed during the set. They cannot represent the unsteady behavior of the wind, the sea state modeled by the heading, the trim or the AWA and the repercussion of a variation on the sail boat equilibrium. Sailors know that adjustments to go fast in a steady state are not the same than in waves and shifty wind ones.

\section{EXPERIMENTAL APPARATUS}

\section{$2.1 \quad$ SENSORS SITING}

Full scale testing is performed on a J80 which principal dimensions are presented in table 1 . Sensors have to fit to the normal sailing configuration without disturbing the flow or the load. Figure 1 shows the position of all the sensors on the J80. 7 instrumented turnbuckles take the place of the 6 shrouds turnbuckles, V1, V2 and D1 starboard and portside, and the forestay chain plate. Instrumented shackles are disposed on all the sail load points. Five are mounted on the main sail: outhaul, sheet, halyard, cunningham and boom vang, three on the jib: sheet, halyard and tack. A ninth shackle is placed on the backstay. The 16 load sensors are linked to two dedicated analogical data acquisition and synchronization Spiders8 from HBM located inside the boat. Four analogical cameras are fixed on the top mast, two on the real top recording the main and two just under the forestay hound point recording the jib. Additional cameras are fixed on the roof, recording the crew and the sail foot. The Motion sensor Xsens MTi-G is placed on the point F, the rotation center of the hull for the small angle at $0^{\circ}$ heel angle. An ultrasonic 3D anemometer is fixed on the top mast and a loch has been installed on the J80 hull. Wire displacement sensors are fixed between the main car and the boom and the jib car and the clew to measure the sheet length. A ruder angle sensor is fixed on the helm basis. A fluxgate compas and a GPS are used inside the boat.

Table 1. Principal dimension of a J80

\begin{tabular}{|c|c|c|}
\hline \multicolumn{3}{|l|}{ HULL } \\
\hline Length over all (m) & & 8.50 \\
\hline Length of water line (m) & & 7.50 \\
\hline Maximum breadth (m) & & 2.49 \\
\hline Draft (m) & & 1.50 \\
\hline Disp (ton) & & 1.45 \\
\hline \multicolumn{3}{|l|}{ SAILS } \\
\hline I luff length (m) & 8.04 & 8.41 \\
\hline $\mathrm{P} \quad$ goose neck $(\mathrm{m})$ & 8.92 & 1.04 \\
\hline $\mathrm{J} \quad \mathrm{E}(\mathrm{m})$ & 2.70 & 3.23 \\
\hline
\end{tabular}

\section{$2.1 \quad$ LOAD MEASUREMENT}

\section{1 (a) Dedicated force sensors}

The use of classical force sensors as S sensors has been put apart because their oversize and their weight needed to modify the rigging and restrained to get all the measurement points. That is the reason why turnbuckles and shackles have been instrumented with stress gauges and substituted to the basic fittings in collaboration with HBM, a company specialized in measurement. Instrumented shackles and turnbuckles are equipped by a load resistive cell giving traction information shown in figure 3 in the final stage of their development. The resistive cell is linked to the data acquisition hardware with a string.

Table 2. Instrumented turnbuckles sensibilities and errors precision

\begin{tabular}{|c|c|c|c|c|c|c|c|c|}
\hline & & V1st & D1st & forestay & D1po & V1po & V2po & V2star \\
$\mathrm{Se}$ & $\mu V / V / k g$ & 1.765 & 1.746 & 1.791 & 1.760 & 1.843 & 1.736 & 1.668 \\
$\mathrm{E}_{\text {pre }}$ & $\%$ & 0.59 & 0.57 & 0.38 & 0.29 & 0.47 & 0.42 & 0.31 \\
$\mathrm{E}_{\text {pre }}$ & $\pm k g$ & 5.87 & 5.69 & 3.77 & 2.92 & 4.75 & 4.24 & 3.15 \\
\hline
\end{tabular}

\section{1 (b) Instrumented turnbuckles}

Instrumented turnbuckles (Fig. 3) are identical to the one used in navigation, Sparcraft turnbuckle $116 \mathrm{~mm}$ for $\emptyset 5 \mathrm{~mm}$ wire. The same adjustment for the initial load in the rigging can be done. A load gauge full bridge is stuck on two flat lugs symmetrically machine-cut on the turnbuckle shank linked to the chain plate. Turnbuckles, because of their thin shape, work in pure traction effort. The maximum designed load is $10000 \mathrm{~N}$. Calibration with a HBM measurement standard load sensor presents no repeatability problem and the precision error determination is simple to get. Table 2 gives turnbuckles sensibilities and precision errors.

\section{1 (c) Instrumented shackles}

Important $\mathrm{R} \& \mathrm{D}$ has been done to calibrate instrumented shackles, from a Whishard $\varnothing 6 \mathrm{~mm}$, which behavior during first calibration was subject to many interrogations. 


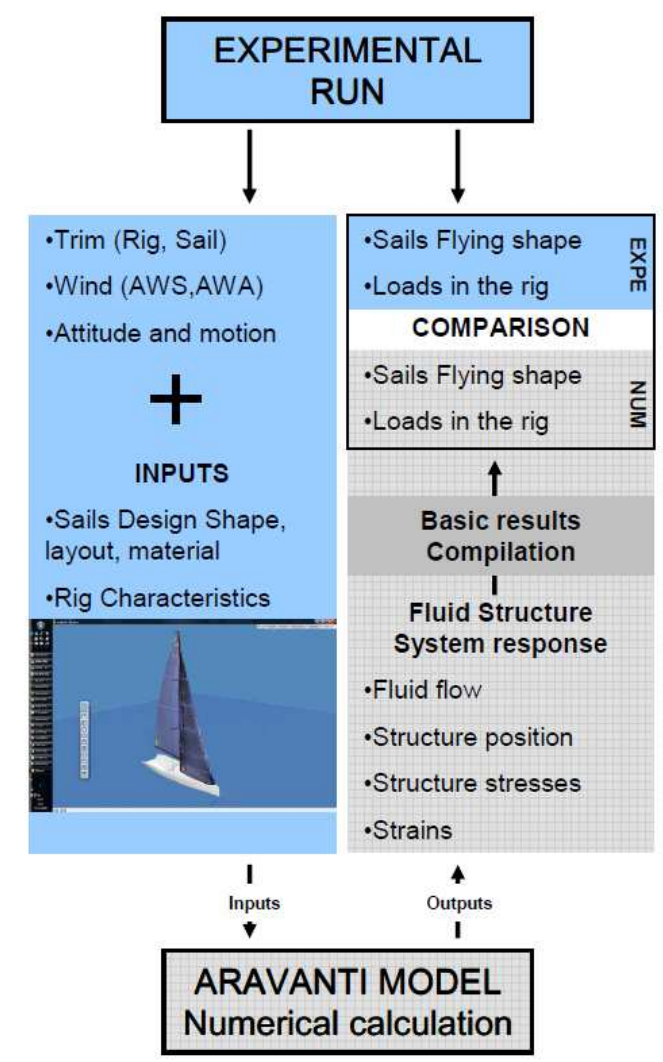

Figure 2. Methodology of the numerical/experimental comparison data.

Calibration procedure and shackle shape has been upgraded. The first step was to machine-cut a diabolo, as shown in figure 3 , fitted to the pin in order to keep the tension on the symmetry axis. The D shape of the shackle is determined to be a cause of non linearity. The shackle doesn't work in pure traction and the measure is polluted by compression. In order to offset, both branches of the shackle have been equipped by a connected full gauge bridge to average the load in each side and delete the compression effect. The asymmetry of the pin, threaded on a side and linked by a pivot on the other one, was shown to be a source of non repeatability. The shackle was machine-cut to have two bores and the pin was replaced by a bolt with nut, clamp on branches. Calibration of the last upgraded shackles gives really good results and an absolute error inferior to $50 \mathrm{~N}$. Results presented in this paper were obtained with the non final version shackle which has an absolute error around $75 \mathrm{~N}$.

\section{1 (d) Shackle calibration}

The calibration process was set up to reflect the reality and to make sure that sensors were studied in the same state than in sailing condition. Shackles were pulled by three in serial between two Dynema splices in order to simulate the tension of a sheet. The maximum designed load is $5000 \mathrm{~N}$ but first navigation recordings permit to recalibrate the measuring range. Shackles supported a basket loaded and unloaded progressively with plumb weight from 0 to $3500 \mathrm{~N}$ on 7 steps. Normal distribution is characterised by a probability density function similar to a bell curve centred on the mean value, by a third order moment, Skewness $\lambda$ equal to 0 which represents the symmetry and a forth order moment, Kurtosis coefficient $\beta$ equal to 3. Regarding the condition of calibration and the repartition of the results shown in figure 4, we assume that measurements follow a normal distribution and that errors determination probabilistic tools calculated to a Gaussian variable can be used. With this hypothesis, the precision error is the root of the sum of the squared errors:

$$
E_{\text {pre }}=\sqrt{E_{h}^{2}+E_{l}^{2}+E_{f}^{2}}
$$

Calibration results are measured for both increasing and decreasing loads in order to distinguish hysteresis error $E_{h}$ from linearity and fidelity errors $E_{l}$ and $E_{f}$. Errors depend on the measurement range MR of the studied sensors. The 2 linear regressions and errors are represented in figure 4 .

$$
E_{h}=\frac{\Delta y_{h} \max }{\operatorname{Se}(M R)}
$$

$\Delta y_{h}$ max represents half of the maximum gap between the 2 linear regressions.

$$
E_{l}=\frac{\Delta y_{l} \max }{\operatorname{Se}(M R)}
$$

$\Delta y_{l}$ max represents the maximum gap between a measurement and its corresponding linear regression.

$$
E_{f}=\frac{2 \sigma \max }{\operatorname{Se}(M R)}
$$

$\sigma \max$ represents the maximum standard deviation calculated for both cases.
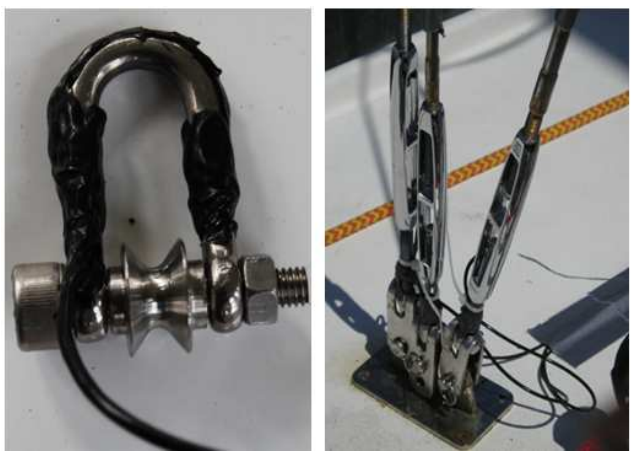

Figure 3. Gauge-fitted shackle and turnbuckles designed for the probe-fitted J80. Load cells are under the black water tight mastic.

\subsection{SAIL SHAPE MEASUREMENT}

A set of three parallel stripes is applied to each sail located at heights of $20 \%, 40 \%$ and $70 \%$ of the luff length. Cameras on the top mast get pictures of full stripes and foot. Images processing from movies are used to measure flying shape parameters defined in figure 5 . 
Different sail analysis softwares have been tested: ISIS, ASA and SailVision. a)

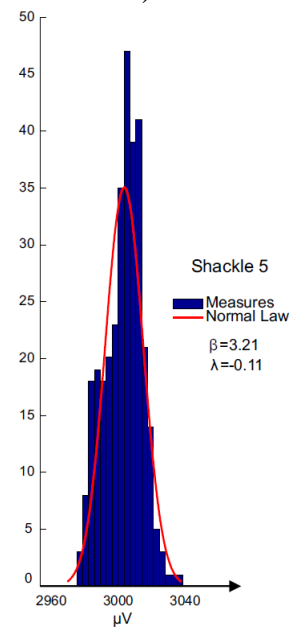

b)

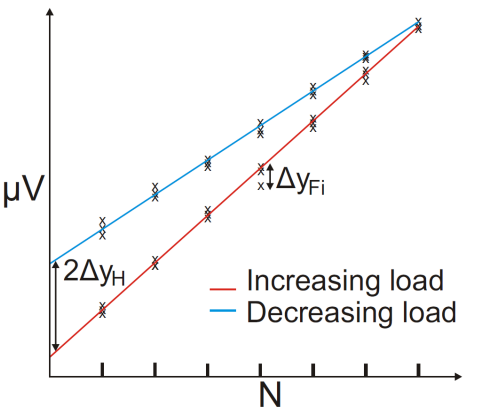

Figure 4. a) Example of the comparison between the measurements and the normal distribution. Coefficients $\lambda$ and $\beta$ confirm the Gaussian distribution.

b) Linear regression, fidelity and hysteresis gap representation for a full calibration process (schematic enlarged view).

\section{2 (a) Cameras distortion}

To correct the lens distortion, cameras are calibrated using a method based on the work of Zhang [5]. The method has been inspired from the camera calibration toolbox for Matlab. Images are corrected in post processing with the distortion coefficient determined for each camera.

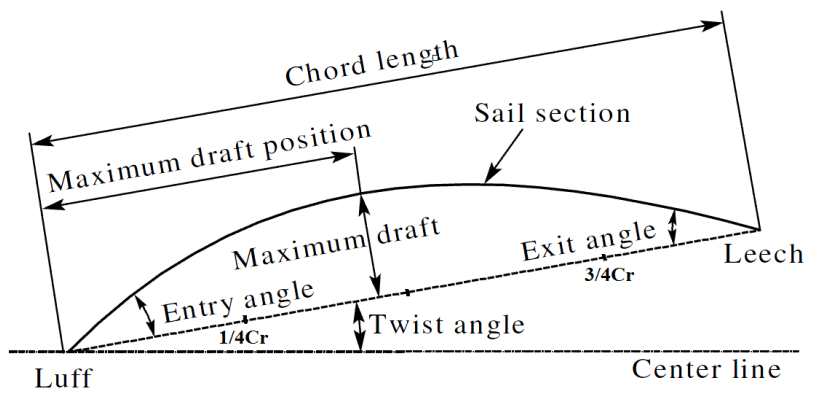

Figure 5. Definition of the flying shape parameters

\section{2 (b) Cameras calibration}

Stripes are designed to belong to a plane parallel to a reference plane $\mathrm{Rf}$, at a known altitude. Two calibration grids are fixed on the deck to represent jib and main planes Rf. Images 2D-data generation are transformed in 3D-data in the world coordinate system with this hypothesis. Angles between the optic axis of the camera and the normal to Rf, illustrated in figure 6 is minimized during the installation for an obvious perspective issue but cannot be deleted. Using the same method, the residual angle and the exact position of the camera retinal frame are calculated and used to correct the perspective effect during the analysis of the stripe.

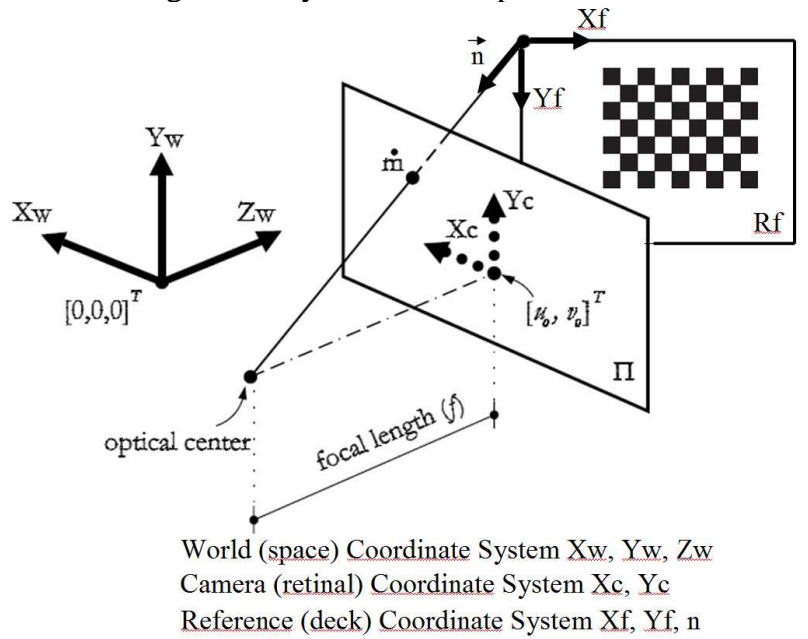

Figure 6. Coordinate systems of the calibration grid fixed on the deck

3D transposition and flying shape parameters determination have been calibrated. The equivalent of a sail with 3 parallel stripes is drawn on the wall of a known diameter cylindrical room. Stripes geometry and angle are exactly calculated from the room dimensions. A camera is fixed on a calibrated support and pictures of the drawn stripes are taken from different cameras positions. Table 3 compares the parameters calculated from the pictures with softwares ASA and ISIS to the values geometrically computed from the cylindrical shape. ASA gives only relative information based on the computation of the chord length from the determination of luff and leech points.

Table 3. Comparison of sail analysis softwares on calibrated drawn visualization stripes. $\theta$ is the entry and exit angle which are the same for this cylindrical geometry.

\begin{tabular}{|c|c|c|c|c|c|c|}
\hline \multicolumn{7}{|c|}{ drawn stripes parameters } \\
\hline stripes & $\mathrm{H}(\mathrm{m})$ & Chord (m) & $\theta\left(^{\circ}\right)$ & $\begin{array}{c}\text { camber } \\
\text { (\%chord) }\end{array}$ & $\begin{array}{l}\text { position } \\
\text { (\%chord) }\end{array}$ & Twist $\left({ }^{\circ}\right)$ \\
\hline 0 & 0 & 1,81 & 28,01 & 6,14 & 50 & 0,00 \\
\hline 20 & 93 & 1,40 & 21,54 & 4,71 & 50 & 3,23 \\
\hline 40 & 186 & 1,01 & 15,52 & 3.39 & 50 & 6.24 \\
\hline 70 & 279 & 0,46 & 7,00 & 1,53 & 50 & 10,50 \\
\hline precision & 0.01 & 0.01 & 0,15 & 0,03 & 0,03 & 0,08 \\
\hline \multicolumn{7}{|c|}{ ASA calculation } \\
\hline & & & $\Delta \theta$ & $\begin{array}{l}\Delta \text { camber } \\
\text { (\%chord) }\end{array}$ & $\begin{array}{l}\Delta \text { position } \\
\text { (\%chord) }\end{array}$ & $\Delta$ Twist $\left({ }^{\circ}\right)$ \\
\hline & & & 4.19 & -0.38 & -1.20 & -0.27 \\
\hline & & & -2.72 & 0.24 & 0.60 & -0.66 \\
\hline & & & -2.32 & 0.03 & 3.60 & -1.33 \\
\hline & & & 0.26 & -0.01 & -16.20 & 0.13 \\
\hline \multicolumn{7}{|c|}{ ISIS calculation } \\
\hline & & & & $\begin{array}{l}\Delta \text { camber } \\
\text { (\%chord) }\end{array}$ & $\begin{array}{l}\Delta \text { position } \\
\text { (\%chord) }\end{array}$ & $\Delta \operatorname{Twist}\left({ }^{\circ}\right)$ \\
\hline & & & -10.19 & -0.36 & -0.20 & 0.00 \\
\hline & & & 4.14 & 0.51 & -3.20 & -0.27 \\
\hline & & & -0.08 & 0.09 & -7.60 & -0.66 \\
\hline & & & 3.60 & 0.63 & 13.10 & 0.40 \\
\hline
\end{tabular}

ASA gives really good results, whatever the camera position. ISIS is really camera position sensitive and results suffer when the angle between the optic axis of the camera and the normal to $\mathrm{Rf}$ increases. Stripes recognition is a long manual procedure for both software. 
A calibration grid is placed on the floor, at the same level of the drawn sail foot, in order to calibrate the camera position determination procedure. The calibration grid is smaller than the real deck grid. The calibrated camera support gives 3D coordinates, compared to extrinsic camera coordinate calculated by a method inspired from calibration toolbox for Matlab and the work of Zhang[5]. This method enables to locate precisely the cameras in space as shown on figure 7.

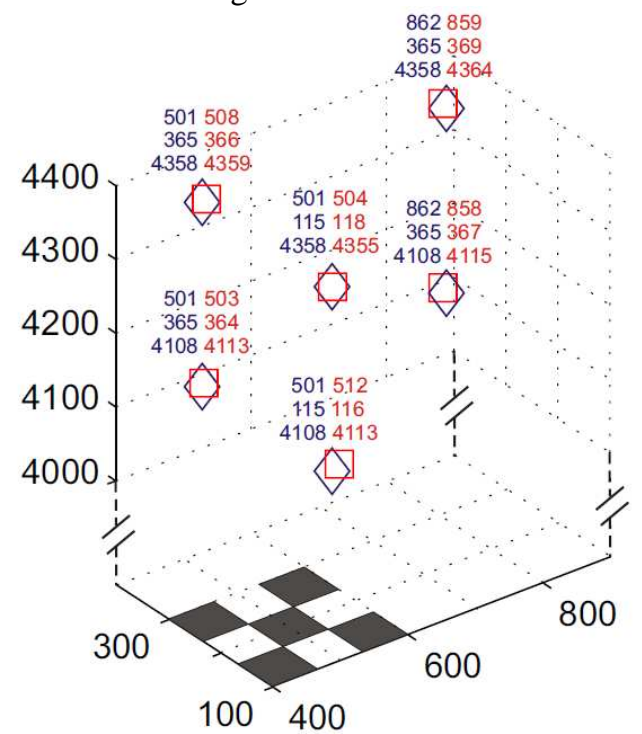

Real camera positions $\triangle$ Calculated camera positions

Figure 7. Comparison between the calibrated and calculated cameras 3D coordinates.

\section{$2.3 \quad$ NAVIGATION DATA}

Table 4. Navigation sensors parameters and accuracy

\begin{tabular}{|c|c|}
\hline \multicolumn{2}{|c|}{ XSENS Static accuracy } \\
\hline $\mathrm{roll} / \mathrm{pitch}$ & $0.5 \mathrm{deg}$ \\
\hline heading & 1 deg \\
\hline Angular resolution & $0.05 \mathrm{deg}$ \\
\hline alignement error & $0,1 \mathrm{deg}$ \\
\hline GPS update rate & $4 \mathrm{~Hz}$ \\
\hline \multicolumn{2}{|c|}{ GPS Furuno } \\
\hline Position & Accuracy \\
\hline GPS & $10 \mathrm{~m}$ \\
\hline DGPS & $5 \mathrm{~m}$ \\
\hline WAAS & $3 \mathrm{~m}$ \\
\hline GPS update rate & $1 \mathrm{~Hz}$ \\
\hline \multicolumn{2}{|c|}{ WINDMASTER gill instrument } \\
\hline Wind speed Range & $0-45 \mathrm{~m} / \mathrm{s}$ \\
\hline Resolution & $0.01 \mathrm{~m} / \mathrm{s}$ \\
\hline direction Resolution & $0.1^{\circ}$ \\
\hline \multicolumn{2}{|c|}{ Loch Navman } \\
\hline Resolution 0-20kts & $0,01 \mathrm{kts}$ \\
\hline Resolution 20-30kts & $0,1 \mathrm{kts}$ \\
\hline
\end{tabular}

The instrumented sail boat has the classical navigation equipment found in all cruiser. Some instruments have been updated from the basic fittings to control the acquisition. The GPS position is directly read by the software. The 3D acoustic anemometer WindMaster located on the top mast gives information on vertical flow with the $\mathrm{z}$ component. It gives an apparent wind measurement. The sea yacht attitude is recorded by the motion sensor XSENS MTI-G, a GPS aided Attitude and Heading Reference System. This 6DOF measurement unit is used on the auto-pilot on some IMOCA 60' boats. Table 4 sets up navigation sensors parameters and accuracy.

\subsection{REAL TIME AND SYNCHRONISATION}

The aim of the instrumentation is to record unsteady phenomena. Measurements have to be linked to the other in order to be able to "play" synchronized full movie of the navigations. Difficulties are in the important number of sensors with heteroclite physical measurements, in the different signals type and frequency. Recordings are shared on two different computers, one dealing with sail shape, the second dealing with the other sensors. Both are synchronized with a GPS clock. A LabView real-time acquisition and synchronization home made software is based on the principle of a sensor information frame for each system clock top, sized up by the highest acquisition frequency. Oversampling is done for the sensor with low frequency acquisition as the GPS or log. The software is able to support $10 \mathrm{~Hz}$ acquisition.

\section{EXPERIMENTAL PROCEDURE}
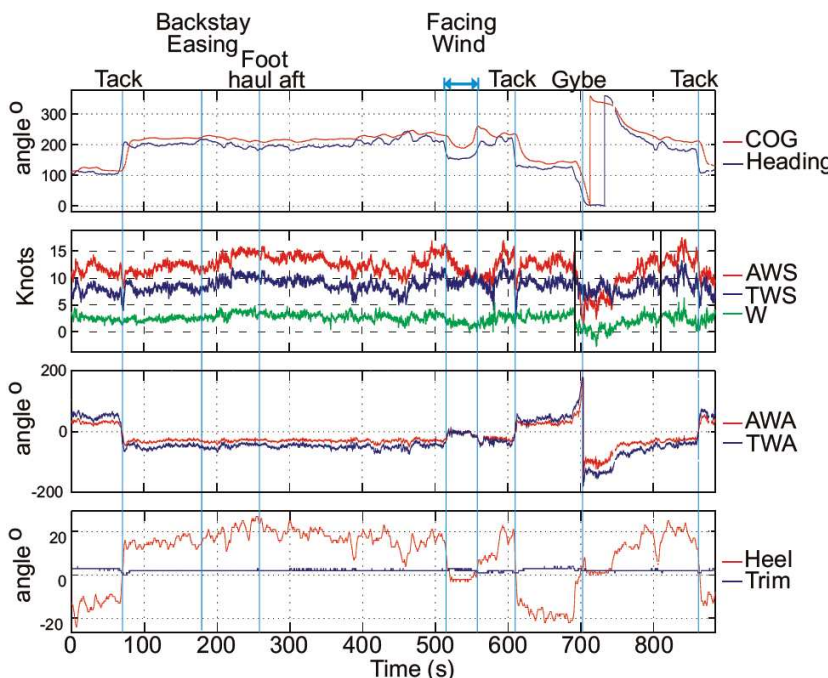

Figure 8. Wind and boat attitudes recorded data for a $15 \mathrm{~min}$ run with the instrumented $\mathrm{J} 80$.

\subsection{RIGGING ADJUSTMENT}

\section{1 (a) In harbour presettings}

Rigging adjustment is identical to regatta, and Num/Expe comparison is made on shroud loads. Adjustments are based on the gap between the turnbuckle 2 threaded rods and the load is controlled. To be sure that the simulation is made with the same adjustment (rake, hogging) pictures of the boat are made, from a known point, on the port in calm wind condition. Pictures are superposed to the simulation to tune the real position. Mast and shrouds 
wires mechanic behavior is studied in laboratory. Parameters are loaded in the code.

\section{1 (b) In navigation}

Length of main and jib sheets are measured by a wire displacement sensor based on an incremental coder. The main car is kept on the centre line, and the trimmer only adjusts the main sheet, measured from the car to the hound point on the boom. The jib sheave is blocked in a position during all navigation and the length is measure from the car block to the clew.

Taking apart sheets, all adjustments are announced, voice recorded and dated. Sheet in or case out are short and material. Figure 8 shows wind and boat attitude data for a 15 minutes run. Tacks and principal adjustments are noticed.

\section{$3.2 \quad$ STEADY STATE}

First calculation is made for a steady state. The steady state is $10 \mathrm{sec}$ in the $15 \mathrm{~min}$ run, from time $230 \mathrm{~s}$ to $240 \mathrm{~s}$. The helmsman was keeping the boat in a good port side close haul and the wind and sea condition were steady. Figure 9 shows the steady wind and boat attitudes recorded data during this period. Figure 10 presents the recorded load on the rigging during this steady state. Loads are shared between leeward and windward shrouds, main and jib loads points. Mean values are calculated over this $10 \mathrm{sec}$ duration and the code computes a steady state with these average inputs.
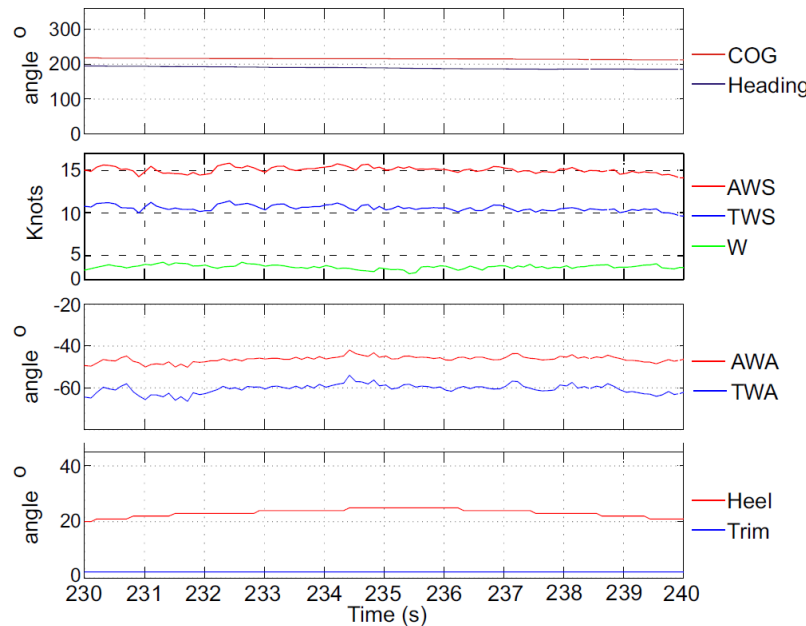

Figure 9. Wind and boat attitudes recorded data for a $10 \mathrm{sec}$ steady state run with the instrumented J80.

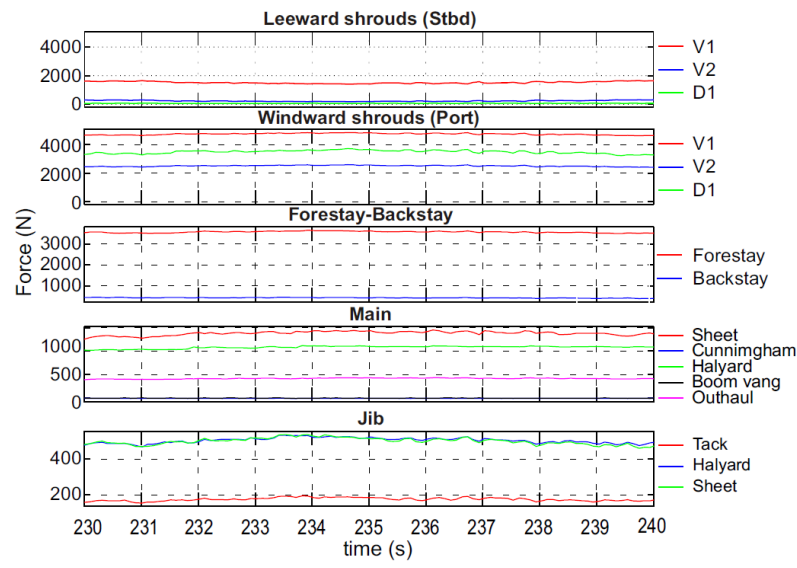

Figure 10. Loads recorded data for a $10 \mathrm{sec}$ steady state run with the instrumented $\mathrm{J} 80$.

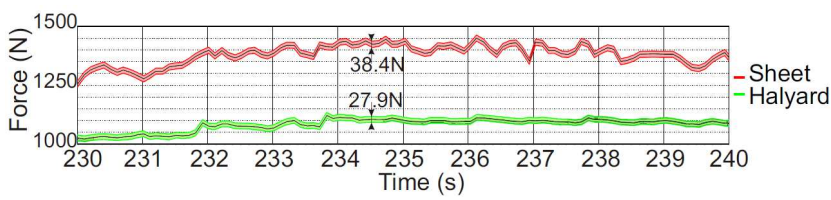

Figure 11. Loads recorded data of the main sail with the precision error bars.

Precision errors of all load sensors are known from the calibration presented in part 2.1. Figure 11 presents a zoom of the main sail load in the sheet and halyard. Errors represent the thickness of the curves. All load results are associated to their error bars.

\subsection{BACKSTAY EASING}

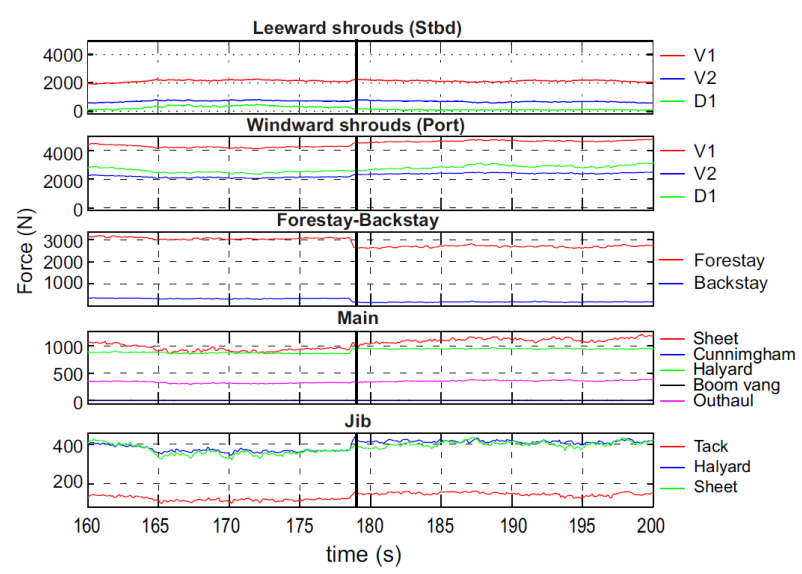

Figure 12. Loads recorded data for a $40 \mathrm{sec}$ run with a backstay easing. The easing occurs at time $179 \mathrm{~s}$ and is represented by a black line.

In the experimental run shown on figure 12, we study the influence of a material adjustment on the flying shape and rigging loads. During the run, the backstay is shortly eased from $350 \mathrm{~N}$ to 0 . The helmsman and the crew keep the boat straight in a portside close haul in order not to disturb the measurements by other happenings. A duration of $40 \mathrm{sec}$ is studied in order to calculate the state of the boat before the easing and the state after. Mean values are calculated for $20 \mathrm{sec}$ before the easing and 20 
sec after. The code calculates 2 steady states separated by the backstay adjustment with the average results data. Figure 13 shows rigging loads of the instrumented J80 during a backstay easing. The adjustment is notified by a vertical black line and occurs at time 179s. Loads gap are clearly visible on the forestay, windward shrouds and jib.

\section{RESULTS}

\subsection{STEADY STATE}

ARAVANTI code models the fluid-structure interaction of the steady state by playing the mean data calculated from the $10 \mathrm{sec}$ period results, which has been determined to be the best. As presented in figure 2, the model inputs from the experimental data are the trim of the rig and the sail, AWA and AWS, boat attitude and motion. Sails design shape, layout, material, rig mechanical characteristics are fixed model inputs for all J80 fluidstructure modelling. Figure 13 presents the Numerical and Experimental comparison on the loads of the instrumented sail boat based on the mean values calculated from the steady state. Windward shrouds loads is very well evaluated with a relative error $<8 \%$. Backstay, main sheet and halyard and jib tack loads have been very well calculated with an error $<5 \%$. The code seems to not perfectly spread the effort in the jib because the forestay load is under evaluated and the jib halyard load is over. Nevertheless jib force balance is respected.

Outhaul load comparison gives bad results because the main foot extremity has a strap, which rounds the boom in order to support the vertical effort and make the outhaul effort in the foot axis. This strap and the resultant friction have not been modelled, so the measured value does not represent the calculated load.

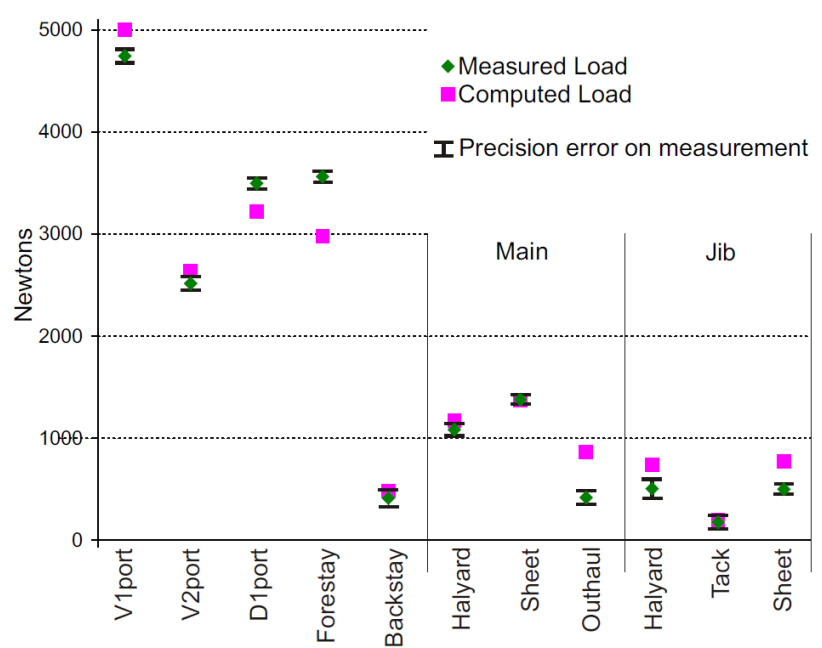

Figure 13. Numerical and Experimental loads comparison on a portside close haul steady state calculation

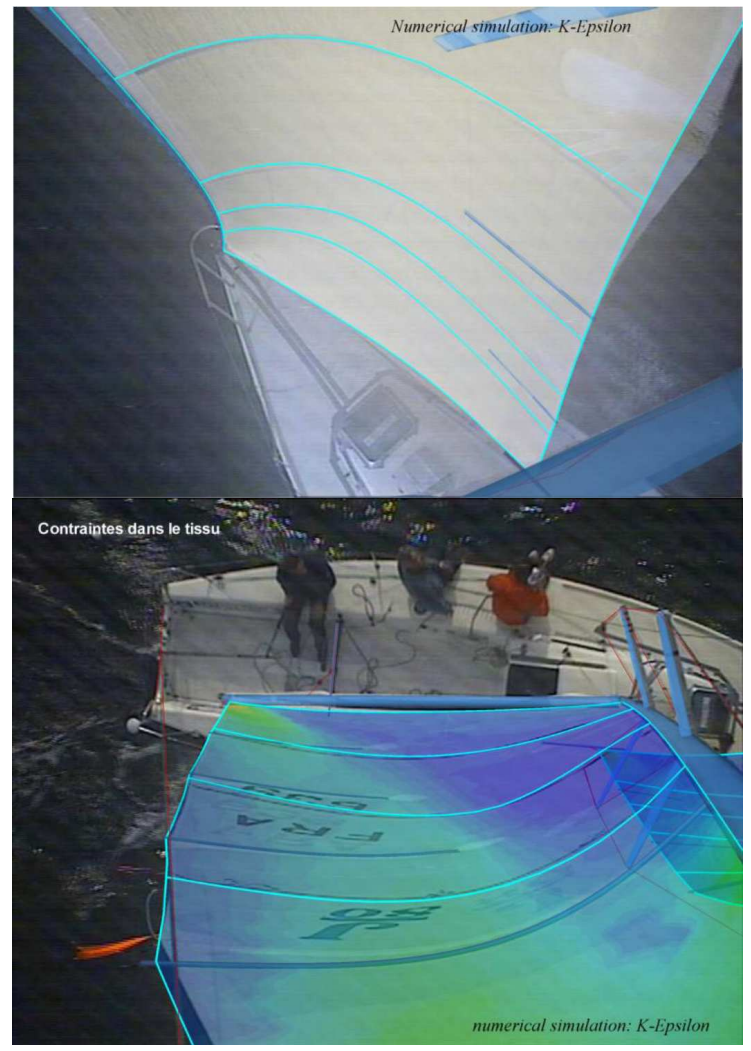

Figure 14. Comparison of the experimental flying shape (picture and dark blue stripes) and the numerical result (superposed picture and stripes in bright blue) on a port tack close haul steady state. Main sail calculation is presented with the stresses in the sail cloth in color scale.

The code gives a graphical representation of the model in order to study the flying shape calculation and to make some numerical/experimental comparison with the pictures taken from the top mast cameras in navigation. Figure 14 shows the superposition of the calculated flying shape of the J80 for the steady state and the picture shot during the $10 \mathrm{sec}$ run. Calculated sails shape matched very well the recorded one, stripes fitting nicely between each other. The experimental jib was modified and the top batten was changed, which explains the angle in the picture. Rig and boom calculated fit very well to the picture as shows the blue superposition.

\section{BACKSTAY EASE}



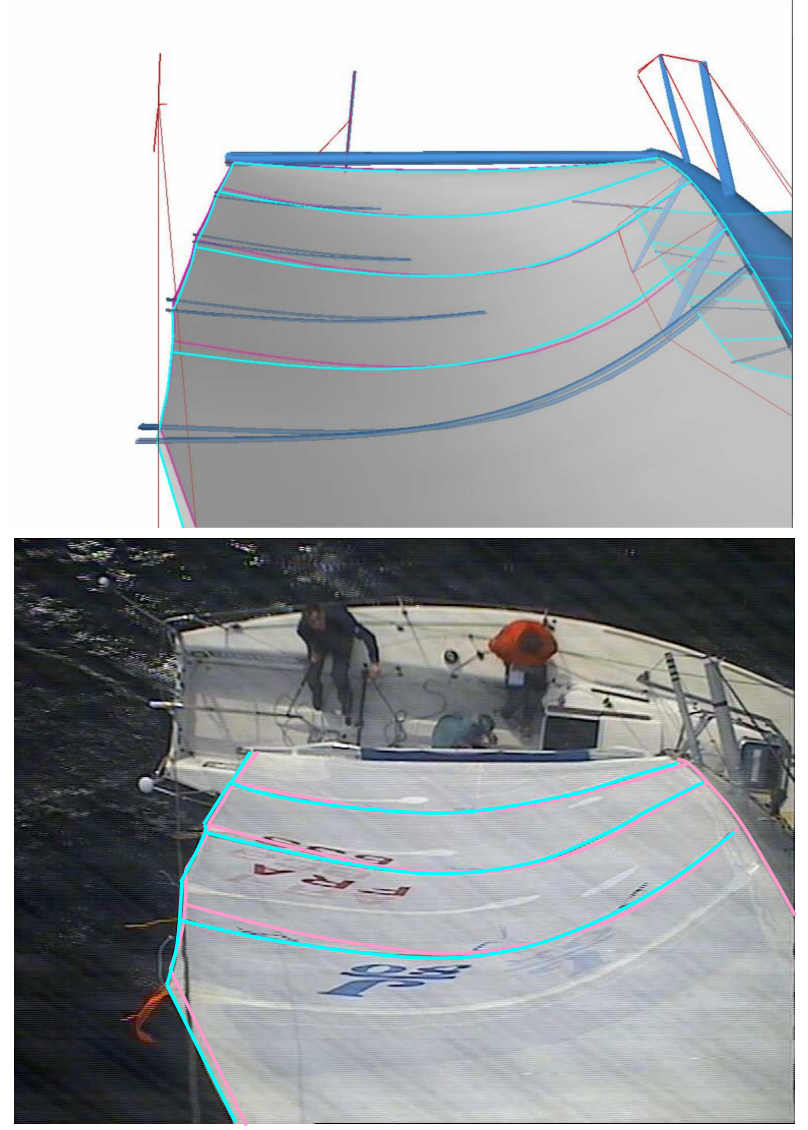

without backstay load

with backstay loads

Figure 15. a) Comparison of the calculated flying shape before and after a $150 \mathrm{~mm}$ backstay ease.

b) Comparison of the recorded flying shape before and after the backstay ease.

ARAVANTI code models the Fluid Structure Interaction of the $15 \mathrm{sec}$ period before and after the backstay ease. The calculation inputs are average values of the 2 periods. Because of the small difference of sailing condition before and after the ease, the comparison of the loads presents no particular interest. We will focus our interest on the flying shape. Figure 15 presents the comparison of the computed $150 \mathrm{~mm}$ backstay ease and the comparison of the recorded backstay ease. The stripes, luff and leech have been underlined. Both cases, computed and recorded, start with the same sailing parameters. Both exhibit the expected modification of the flying shape: the twist decreases and the maximum camber increases when the backstay load decreases. Table 5 and 6 present the calculated stripes parameters from ARAVANTI calculation which confirm the tendencies. Here, the main shape changes due to the backstay ease is moderate because the initial load in the backstay was small, for there is only 10 knots breeze. It is remarkable that such a light trim variation is actually measured by the experimental system and well predicted by the model.
Table 5. Stripes parameters with backstay load

\begin{tabular}{|c|c|c|c|c|c|}
\hline \multicolumn{6}{|c|}{ JIB } \\
\hline PROFIL & $\mathrm{H} \mid \mathrm{m}]$ & POS[\%] & VAL[\%] & ANGLE $\left.\left.\right|^{\circ}\right]$ & TWIST $\left.^{\circ}\right]$ \\
\hline $65.0 \%$ & 5.94 & 44. & 15.4 & -28.3 & -20.2 \\
\hline $46.0 \%$ & 4.39 & 39. & 15.3 & -20.6 & -12.5 \\
\hline $32.5 \%$ & 3.30 & 36. & 14.2 & -15.6 & -7.5 \\
\hline $20.0 \%$ & 2.31 & 36. & 12.3 & -12.1 & -3.9 \\
\hline FOOT & 0.71 & 55. & 2.0 & -8.1 & 0.0 \\
\hline \multicolumn{6}{|c|}{ MAIN } \\
\hline PROFIL & $\mathrm{H} \mid \mathrm{m}]$ & POS[\%] & VAL[\%] & ANGLE $\left[^{\circ}\right]$ & $\operatorname{TWIST}^{\circ}$ \\
\hline $70.0 \%$ & 7.61 & 41. & 12.6 & -16.9 & -12.3 \\
\hline $43.0 \%$ & 5.31 & 37. & 11.9 & -11.4 & -6.8 \\
\hline $18.5 \%$ & 3.30 & 45. & 7.6 & -7.3 & -2.6 \\
\hline FOOT & 1.81 & 44. & 2.1 & -4.6 & 0.0 \\
\hline
\end{tabular}

Table 6. Stripes parameters after backstay ease

\begin{tabular}{|c|c|c|c|c|c|}
\hline \multicolumn{6}{|c|}{ JIB } \\
\hline PROFIL & $\mathrm{H}[\mathrm{m}]$ & $\operatorname{POS}[\%]$ & VAL $[\%]$ & $\operatorname{ANGLE}\left[^{\circ}\right]$ & $\operatorname{TWIST}\left[^{\circ}\right]$ \\
\hline $65.0 \%$ & 5.93 & 44. & 16.1 & -27.5 & -19.4 \\
\hline $46.0 \%$ & 4.38 & 39. & 15.8 & -20.0 & -11.9 \\
\hline $32.5 \%$ & 3.29 & 35. & 14.6 & -15.2 & -7.1 \\
\hline $20.0 \%$ & 2.31 & 36. & 12.3 & -11.8 & -3.7 \\
\hline FOOT & 0.71 & 55. & 2.0 & -8.1 & 0.0 \\
\hline \multicolumn{6}{|c|}{ MAIN } \\
\hline PROFIL & $\mathrm{H}[\mathrm{m}]$ & $\operatorname{POS}[\%]$ & VAL[\%] & $\operatorname{ANGLE}\left[^{\circ}\right]$ & $\operatorname{TWIST}\left[^{\circ}\right]$ \\
\hline $70.0 \%$ & 7.61 & 41. & 13.6 & -15.7 & -11.4 \\
\hline $43.0 \%$ & 5.32 & 37. & 12.6 & -10.6 & -6.2 \\
\hline $18.5 \%$ & 3.31 & 45. & 8.0 & -6.7 & -2.4 \\
\hline FOOT & 1.82 & 44. & 2.2 & -4.3 & 0.0 \\
\hline
\end{tabular}

\section{CONCLUSION}

A dedicated instrumentation system has been developed on a J80 sail boat to record data in real navigation conditions to be able to validate a fluid structure interaction model applied to the aero elastic problem of yacht sails (ARAVANTI). The system is made to measure the navigation data, the yacht attitudes and motion, the loads in the standing and running rigging and the sails flying shape. Special care was devoted to measurement calibration and uncertainties. Recorded environmental data and yacht attitudes are used as inputs to the model, as well as sails and rig mechanical characteristics. The sails flying shape and loads in the rig computed by the model are then compared to the ones recorded during the experiment. Two runs have been considered: a "steady state" in which the experimental records have been averaged over $10 \mathrm{sec}$ in constant conditions; a trim change where the results have been compared with and without tension in the backstay, other parameters remaining the same. In both cases, the experimental and numerical results match very well. The steady state case enables to focus on the loads in the rigging and gives a good comparison. The backstay ease gives a good example of the model capacity to model the modification of the flying shape due to trim change.

The instrumentation system is still under development to improve its capacity to measure strongly unsteady conditions (waves, wind and course changes...). The measurement campaign presented in this paper was made with home made data acquisition software which was limited to a low frequency and not optimal for data synchronisation. In order to improve the system (better synchronisation, higher picture frequency) a new 
acquisition process based on the software RTmaps from INTEMPORA is under development and further experimental campaigns are planned.

\section{ACKNOWLEDGEMENTS}

This work has been done in the VOILENAV project supported by the French Naval Academy, Ecole Navale. The authors are grateful to K-epsilon for continuous collaboration about ARAVANTI model. Technical support from BSG development DeltaVoiles and Intempora is also acknowledged.

Thanks also to Didier Munck for his valuable involvement in this project.

\section{REFERENCES}

1. MASUYAMA Y. FUKUSAWA T. 'Database of sail shapes versus sail performance and validation of numerical calculations for the upwind condition' $J$ Mar Sci Technol, 2009

2. LE PELLEY D.J. MODRAL O. 'V-SPARS: A combined sail and rig recognition system using imaging techniques' $3^{\text {rd }}$ High Performance Yacht Design Conference Auckland, New Zeeland, December, 2008

3. HANSEN, H. JACKSON, P. HOCHKIRCH, K. 'Comparison of wind tunnel and full-scale aerodynamic sail force measurements' $2^{\text {nd }}$ High Performance Yacht Design Conference Auckland, New Zeeland

4. CLAUSS G. HEISEN W. 'CFD Analysis on the flying shape of modern yacht sails' $12^{\text {th }}$ International Congress of the international Maritime Association of the Mediterranean, 2005

5. ZHANG. Z 'A flexible new technique for camera calibration' IEEE Transactions on Pattern Analysis and Machine Intelligence, 2000.

6. ROUX, Y., DURAND, M., LEROYER, A., QUEUTEY, P., VISONNEAU, M., RAYMOND, J., FINOT, J.M., HAUVILLE, F. and PURWANTO, A., 'Strongly coupled VPP and CFD RANSE code for sailing yacht performance prediction' 3rd High Performance Yacht Design Conference, Auckland, New Zeeland, December, 2008.

\section{AUTHORS BIOGRAPHY}

Benoît Augier is $\mathrm{PhD}$ student in the Research Institute of the French Naval Academy (IRENav). He is studying the Fluid Structure Interaction on soft surfaces with a strong application to sails. He is particularly in charge of the experimental work.

Frederic Hauville and Patrick Bot are associate professors at IRENav, specialised in fluid mechanics. They are studying Fluid Structure Interaction and marine renewable energy. They have been working on FSI of sails for many years and started to develop measurements on sailing yachts in 2000 .

Mathieu Durand's current position is researcher at Kepsilon company and is preparing his $\mathrm{PhD}$ with Ecole
Centrale de Nantes and IRENav. His work deals with numerical FSI modelling.

The four authors are J80 experienced hobby sailors. 